\title{
FORMATION OF A SCALE FOR EVALUATION OF THESIS QUALITY IN MD CURRICULUM IN WEST BENGAL
}

\author{
${ }^{1}$ Dr. Mrinal Pal*, ${ }^{1}$ Dr. Uttam Kumar Roy, ${ }^{2}$ Dr. Sourav Sau, ${ }^{3}$ Dr. Subinay Datta \\ ${ }^{1}$ Department of Pharmacology, Burdwan Medical College, Burdwan, WB, India \\ ${ }^{2}$ Department of Radiotherapy, Burdwan Medical College, Burdwan, WB, India \\ ${ }^{3}$ Department of Biochemistry, Burdwan Medical College, Burdwan, WB, India
}

\begin{abstract}
:
Back ground: Thesis is an obligatory part of Medical post graduate or post doctoral courses under West Bengal University of Health Sciences. The purpose of this thesis work is to make the doctors familiar with research methodology. There is no procedure or scale to evaluate the quality of thesis works in our state.

Aim: Formation of a scale for evaluation of thesis work \& using this scale evaluation of ongoing thesis works of this medical university.

Procedure: At first we develop a scale containing five factors Format, Study design; Knowledge of the post graduate trainee, new ideas, Literature reviewed and validation of that scale was done. With the help of this validated scale we have evaluated 135 thesis works of outgoing post graduate medical students.

Result: After evaluation it was found that most of the thesis work falls in the excellent category. Very few are exceptional as well as good or acceptable. The scale also indicated that the weak areas of the thesis work.

Conclusion: Our scale will indicate the clear picture of quality of a research work including strong and weak areas. This fact will help us in future to plan a better research work.

Key Words: Thesis evaluation, Validated Scale, research methodology
\end{abstract}

\section{INTRODUCTION:}

A desertion or thesis is a document submitted in support of candidature for an academic degree or professional qualification presenting the authors research and findings 1,2 . Thesis is obligatory for postgraduate MD/MS,DM/Mch and PhD courses(www.thewbuhs.org). In recent years, number of research work has increased as a result of increased no of postgraduate seats in West Bengal. The goal of research work is to make doctors familiar with research process, methodology, thesis writing skill, statistical analysis and basic research involving animal experiments. Lack of approved courses for research process before submission of synopsis, places the newly admitted post graduate students in great confusion. Insufficient time is also another contributing factor ${ }^{3}$.In many cases ultimate research work is mere repetition of previous works ${ }^{4}$. This fact leads to few noteworthy scientific contributions ${ }^{5}$.

Evaluation of thesis quality in our setting still lies in infancy. Many centers have their own frame work to have a good quality work. In 2009, ORPHEUS 6 published a paper titled " Towards standards for $\mathrm{Ph} \mathrm{D}$ education in Bio-medicine \& Health Sciences”. Inspired by ORPHEUS, Dutch UMC Medical School has developed guidelines. University of New South Wales (UNSW) formed guidelines in graduate research school. The Sahlgrenska Academy (University of Gothenburg) provides necessary formats for thesis works (www.salgrenska.gu.se)
With this background, we tried to evaluate thesis quality in our institute. As quantitative nature of research work is reflected in its quality, a scale (questionnaire consisting of five questions / items) was conducted and found reliable (measured the value of Chronbach's Alpha) utilized in scoring of the thesis works.

\section{MATERIALS \& METHOD:}

It was an observational study. Total period of study was four months (December 2013-March, 2014). We have collected the soft copy of desertion of 135 outgoing MD students of different Medical Colleges under WBUHS (Batch 2011-14). They are from different disciplines also. We have approached 203 students out of which 115 had given consent regarding evaluation of their thesis works. For blinding purpose we have removed the details regarding the name of the student, name of the guide / co-guide, name of the department \& institution. All research works of the willing candidates were included in this, there were no exclusion criteria.

\section{*For Correspondence:}

Dr. Mrinal Pal

Department of Pharmacology

Burdwan Medical College, Burdwan, WB, India Email-mrinalpal77@rediffmail.com

Mobile-9007593545 
Methodology:

Our evaluation process involves five steps

Step-1:

We prepared a question paper which contains twelve questions, each question focuses one or more features of thesis works. This question paper was placed to fifty two faculty members including guides \& co-guides of different research works. They are selected at random fashion. They were instructed to check the boxes against each question in order of importance. Analysis of this step captures five items regarding thesis being most important. It is to be mentioned here that these items supposed to cover important aspects of thesis. These are Format, Study design, Knowledge of the post graduate trainee(PGT), New ideas, Literature reviewed. Structure of thesis having standard format where objectives with sufficient explanation and back ground are incorporated. Expert literature review which includes recent works and related works, study design including calculation of sample size, new ideas and PGT knowledge are embedded in these items. Application of statistics in analysis of data improves quality of data research works.PGT knowledge includes writing skill of entire thesis presentation and analytic capability to synthesize new relationship and to create complex ideas.

These five items at the end of step 1 becomes 1) Format, 2)Study design,3)Knowledge of the post graduate trainee(PGT),4)New ideas, 5)Literature reviewed and forms a question nature in step 2 .

Step 2: We used five point Likert Scale questionnaires ${ }^{8}$, typical format is as follows

a) Strongly disagree-1

b) Disagree-2

c) No opinion-3

d) Agree-4

e) Strongly agree-5

Scale consists of five questions which are given below.

Q-1: Proper format of WBUHS for thesis makes better quality thesis work

Q-2: New concept /innovative ideas make thesis quality better

Q-3: Knowledge of PGT for making charts, diagrams, proper writing makes thesis quality better

Q-4: Study design if done properly, makes better quality thesis work

Q-5: Expert literature review by PGT results in better quality thesis

Scoring for each item -

\section{A. Format:}

4- Followed accurately

3-overall 60-70\% followed

2-followed somehow

1-poorly / inadequately followed

B. New Ideas:

(C) 2011-14, JDDT. All Rights Reserved 4-original, exploring ideas, darth of literature

3-original (modified in dose, route, sample size, extra objectives

2-Mere repetition (study area is different)

1-meets inclusion criteria only

\section{Design:}

4-highly satisfactory, each phase gives clear picture

3-well designed, statistically sound, sample size explained, duration appropriate, supportive investigation made more balanced

2- Well designed, statistically sound, sample size explained

1- Well designed, statistically sound

\section{Knowledge of the researcher}

4-statistical analysis properly done

3-entire presentation good showing ability to synthesize complex ideas

2-Ability to synthesize charts, diagrams, proper presentation of results with logical arrangements

1- Ability to synthesize charts, diagrams

\section{E. Literature survey:}

4- a) demerits of work visualized from search results

b) can predict future aspect any one of (a) / (b)

3-other related works, able to synthesize new ideas

2-include recent works

1-anyway done

Minimum score for each question is 1 , maximum score for each question is 4.Maximum score of the scale is 20 , minimum 5.

Step 3:

We employed this questionnaires to twenty four experienced teachers (Professor or Associate Professor working under WBUHS, west Bengal) engaged in post graduate teaching and thesis evaluation process. They specify their intensity of feeling in terms of agreement / disagreement. Likert Scale converts qualitative data into a quantitative one facilitating statistical analysis. Cronbach's Alpha is a measure of internal consistency and its represents inter-correlation among items ${ }^{9,10}$. When reliable scale is formed we further stepped forward into step 4.

\section{Step 4:}

For validation of questionnaires we have proceeded towards the evaluation of MD thesis works using our scale, For this purpose we have employed two most experienced professors.We have supplied the soft copy of desertions of 135 outgoing MD students of different Medical Colleges under WBUHS (Batch 2011-14) after removing the details regarding the name of the student, name of the guide / co-guide, name of the department \& institution. 


\section{Step 5:}

The senior most teachers employed by us helped us in the process of evaluation giving score to each item considering adherence of all character in thesis quality. We graded each item in such a way that highest score \& lowest score being five and one. When summated each work gives maximum score 25 and minimum score 5 .

We also specified qualities of work based on scores in following way:

Table 1: quality gradation of work based on scores

\begin{tabular}{|l|l|}
\hline Score & Quality Gradation \\
\hline $20-25$ & Exceptional \\
\hline $15-19$ & Excellent \\
\hline $10-14$ & Very good \\
\hline$<10$ & Good/Acceptable \\
\hline \multicolumn{2}{|c|}{ (Lower the score poor is the quality) }
\end{tabular}

Many centers have their own scoring system for thesis quality evaluation.

\section{Step 6:}

\section{Statistical Analysis and presentation:}

During validation of the scale we got Cronbach alpha score 0.8.Looking at the item-total statistics we get further evidence that all items included in proposed scale are contributing to internal consistency. All items displayed a decrease in alpha value when removed; scale mean \& variance also decreases if any item removed indicating their importance in scale formation and relative contribution. Corrected item-total correction for each item was found to be more than 0.3 and variance if item/items deleted were less than 0.1 .

After evaluation of thesis works using the proposed scale it was found that most of the thesis works were fallen in the excellent category. Very few were exceptional. Very small numbers of thesis were fall in the good/acceptable category. By analyzing the scores it was found that most of the thesis works were very good in the field of thesis design, literature survey and format. But there were poor scoring in the area of new idea \& the knowledge of the researcher.

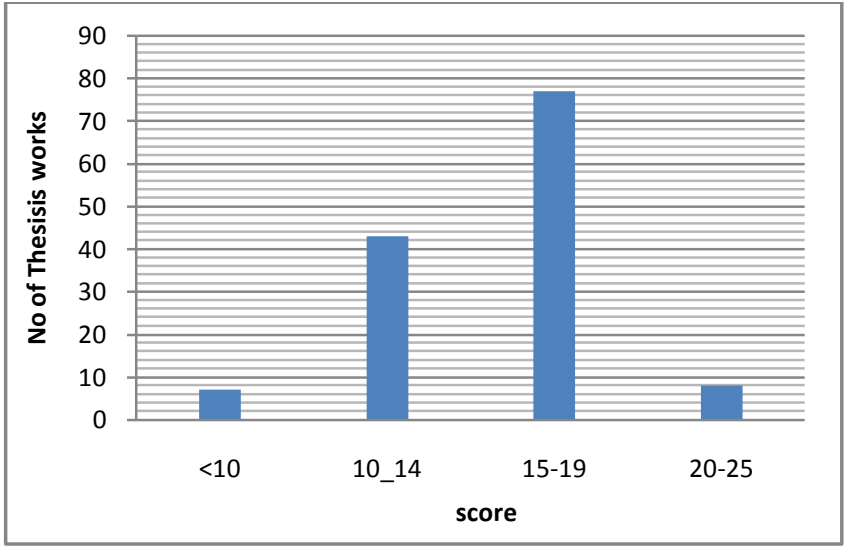

Figure 1: Distribution of all thesis works based quality gradation

\section{DISCUSSION:}

In this study our aim is to form a scale to identify not only good quality research but also to find out the area of weakness of the research. Adequacy of sample size, statistically valid analysis has immense value in deciding a good quality work. It must be kept in mind that research uncovers knowledge of the researchers but the work must have beneficial inspiration in mankind. Here always lie the issues of uncertainty and assessing scientific quality which have no standard solution.

Though we want to evaluate the research quality with the help of our scale which consists of few important items but we should keep it in our mind that quality is also facility and faculty related.

We develop a validated scale with the intention to assess the quality of any research work. Results would be based on fixation criteria of scoring system. Score may vary from one centre to another centre. We have to keep it in our mind that a scale reliable in one centre may not be reliable in other centre.

Our scale will indicate the clear picture of quality of a research work including strong and weak areas. This fact will help us in future to plan a better research work

Acknowledgement: Authors are thankful to Dr. Anindya Dasgupta \& Dr. Supreeti Biswas for their for their constant support \& contribution,

\section{Conflict of interest: None}

\section{REFERENCES:}

1. Singer C, Holloway SWF, Early Medical Education in England in Relation to the Pre-History of the University of London, Med Hist. 1960; 4(1): 1-17.

2. "Research Doctorate Programmes". US Department of Education. 2006-06-18

3. Waring, Marilyn, Thesis survivor stories: practical advice on getting through your PhD or Master's thesis. Victoria University of Wellington Library Auckland [N.Z.]: AUT Media, 2011.

4. Powell R, Evaluation research: An overview. Library Trends2006; 55 (1), 102-120.

5. Gupta V, Postgraduate education in medical pharmacology: A student's. Indian J Pharmacol 2007;39:256.

6. ORPHEUS2009. Fourth European Conference: Setting Standards for PhD Education in Biomedicine and Health Sciences. Aarhus 2009.

7. Patton MQ, Qualitative research and evaluation methods (3rd ed.). Thousand Oaks, CA.: Sage Publications.

8. Allen A, Elaine D, Seaman P, Christopher D, Likert Scales and Data Analyses. Quality Progress 2007, 64-65.

9. Develles RF, Scale Development. Sage Publications 1991; 2433

10. Revelle W ZinbargR, Coefficients Alpha, Beta, Omega, and the glb: Comments on Sijtsma2007,Psychometrika 74 (1): 145154. 